\title{
Dependence of $\mathrm{Al}_{0.48} \mathrm{In}_{0.52} \mathrm{As}$ Schottky diode properties on molecular beam epitaxial growth temperature
}

\author{
A. S. Brown ${ }^{\text {a) }}$ \\ School of Electrical and Computer Engineering, Georgia Institute of Technology, Atlanta, \\ Georgia 30332-0250 \\ P. Bhattacharya ${ }^{\text {b) }}$ and J. Singh \\ Department of Electrical and Computer Engineering, University of Michigan, Ann Arbor, \\ Michigan 48109-2122 \\ P. Zaman and S. Sen ${ }^{\mathrm{c}}$ \\ Department of Electronic Science, University of Calcutta 92, Acharya P. C. Roy Road, Calcutta 700009, \\ India \\ F. Turco \\ Bellcore, 331 Newman Springs Road, Red Bank, New Jersey 07701-7020
}

(Received 3 May 1995; accepted for publication 26 October 1995)

\begin{abstract}
We have observed a degradation in the epitaxial layer quality of AlInAs when it is grown by molecular beam epitaxy at a substrate temperature of about $400{ }^{\circ} \mathrm{C}$ compared to that for alloys grown at 300 and $500{ }^{\circ} \mathrm{C}$. The barrier height and ideality factor of Ti- and Au-AlInAs Schottky diodes also exhibit large spatial variations and dependence on growth temperatures. The observed phenomena can be explained by invoking a kinetic growth model or thermodynamic phase equilibria in the growing surface layer. (C) 1996 American Institute of Physics. [S0003-6951(96)02202-6]
\end{abstract}

The ternary compound $\mathrm{Al}_{0.48} \mathrm{In}_{0.52} \mathrm{As}$ is an important wide-band-gap semiconductor for its use in high-electron mobility transistors (HEMTs) ${ }^{1-4}$ and in optoelectronic devices. There has been a great deal of interest in the properties of Schottky diodes made on $\mathrm{Al}_{0.48} \mathrm{In}_{0.52}$ As for applications in HEMTs and other devices. 5,6 The formation of reliable Schottky diodes depends not only on the formation of the metal contact, but also on the surface and bulk properties of the semiconductor. Indeed, a wide range of values of Schottky barrier heights and diode ideality factors can be measured on seemingly identical materials.

Of the As-based III-V compounds, $\mathrm{Al}_{0.48} \mathrm{In}_{0.52} \mathrm{As}$, lattice-matched to InP, has consistently shown the lowest material quality in terms of optical and electrical properties. Hall data on Si-doped (100)-oriented AlInAs samples indicate clustering into Al-rich and In-rich regions with cluster sizes of approximately $7.0 \mathrm{~nm} .^{7}$ The best reported low temperature photoluminescence linewidth is $10.5 \mathrm{meV},{ }^{8}$ far from the theoretical alloy limited minimum of $3.8 \mathrm{meV} .^{9}$ Raman data also indicate alloy clustering. ${ }^{10}$ Under conditions of thermodynamic equilibrium, the alloy is predicted to have a miscibility gap that results in alloy clustering. ${ }^{9}$

Molecular beam epitaxial (MBE) growth is typically kinetically limited so one would not expect the alloy quality to be affected in the same way. However, we have observed evidence of clustering in the AlInAs alloy system when MBE growth occurs at approximately $400{ }^{\circ} \mathrm{C}$. The optical properties $^{11}$ and surface morphology of the alloy are de-

${ }^{a)}$ Work was done while the author was at Hughes Research Laboratory, Malibu, CA.

${ }^{b)}$ Electronic mail: pkb@eecs.umich.edu

${ }^{c}$ Work was done while the author was at the University of Michigan. graded. Material grown at 300 or $500{ }^{\circ} \mathrm{C}$ has much improved properties. It is believed that this effect is related to the disparity in bond strength energies. These observations have motivated us to carefully study the dependence of Schottky diode properties on alloy growth temperature during MBE and to characterize the spatial variation of Schottky diode properties, in material grown at $520^{\circ} \mathrm{C}$, due to surface segregation effects.

AlInAs layers $(\sim 1 \mu \mathrm{m}$ thick $)$ were grown by MBE in the substrate temperature range of $300-550{ }^{\circ} \mathrm{C}$ at a growth rate of approximately $1 \mu \mathrm{m} / \mathrm{h}$. X-ray photoelectron spectroscopy (XPS) measurements were performed on samples grown at the different substrate temperatures to compare the surface compositions. The samples required deoxidation with an HF solution that could have reduced the magnitude of any observed difference in the surface compositions and introduced small errors in the measured compositions. The composition was determined from the $\mathrm{Al}_{2 p}$ and $\mathrm{In}_{4 d}$ photoelectron peaks. The values of composition obtained were $x_{\text {In }}$ $=0.75$ for the growth at $300^{\circ} \mathrm{C}, x_{\mathrm{In}}=0.80$ for the growth at $400{ }^{\circ} \mathrm{C}$, and $x_{\text {In }}=0.76$ for the growth at $500{ }^{\circ} \mathrm{C}$. These numbers are not absolute measurements of the compositions but do indicate a significant increase in the surface In composition for the sample grown at $400{ }^{\circ} \mathrm{C}$ as compared with the samples grown at 300 and $500{ }^{\circ} \mathrm{C}$.

The barrier height $\phi_{\mathrm{Bn}}$ and ideality factor $n$ of Schottky diodes were estimated from measured forward bias currentvoltage characteristics using the equation:

$$
\phi_{\mathrm{Bn}}=\frac{k T}{q} \ln \left(\frac{120 m_{e}^{*} T^{2} A[\exp (q V / n k T)-1]}{I}\right),
$$

where $A$ is the diode area, $V$ and $I$ are the forward bias and 
current, respectively, and $m_{e}^{*}$ is the electron effective mass. For $\mathrm{Al}_{0.48} \mathrm{In}_{0.52} \mathrm{As}$, a value of $m_{e}^{*}=0.08 m_{0}$ was assumed ${ }^{12}$ in our calculations. Two different experiments were conducted. In the first, Si-doped $n$-type AlInAs layers $(n \sim 5$ $\times 10^{17} \mathrm{~cm}^{3}$ ) were grown with an $n^{+}$buffer layer in order to fabricate Schottky diodes and determine the effect of growth temperature on barrier height. A mesa process was used to fabricate $100 \mu \mathrm{m}$ diam diodes. Ti metal was used to form the Schottky barrier. The average barrier heights were determined from room temperature current-voltage characteristics. Measurements were made on approximately 100 devices per wafer to obtain a significant statistical sampling. The diodes fabricated on material grown at 300 and $500{ }^{\circ} \mathrm{C}$ had similar properties. The average barrier heights were determined to be approximately $0.55 \mathrm{eV}$ and ideality factors were 1.4 for the material grown at $300{ }^{\circ} \mathrm{C}$ and 1.6 for the material grown at $500{ }^{\circ} \mathrm{C}$. The average barrier height and ideality factor for the material grown at $400{ }^{\circ} \mathrm{C}$ were $0.52 \mathrm{eV}$ and 1.9 , respectively.

In the second experiment, done with samples from a different MBE system, the spatial variation of the diode characteristics was more closely investigated. Two sets of wafers were grown. The first consists of a $1 \mu \mathrm{m}$ thick $\mathrm{Al}_{0.48} \mathrm{In}_{0.52} \mathrm{As}$ layer with a thin $(30-50 \AA)$ protective GaAs layer on top grown on $n^{+}$InP. The ternary layer was grown at $520^{\circ} \mathrm{C}$ and at $1 \mu \mathrm{m} / \mathrm{h}$ and was doped $n$ type at a level of $4 \times 10^{16} \mathrm{~cm}^{-3}$ with $\mathrm{Si}$. The second sample consists of a $1.05 \mu \mathrm{m} \mathrm{Al} \mathrm{m}_{0.48} \mathrm{In}_{0.52} \mathrm{As}$ layer doped to the same level $(n=4$ $\times 10^{16} \mathrm{~cm}^{-3}$ ), with a $12 \mathrm{~nm} \mathrm{Ga}{ }_{0.47} \mathrm{In}_{0.53}$ As smoothing layer inserted in between on a $100 \mathrm{~nm}$ heavily doped $(n=2$ $\left.\times 10^{18} \mathrm{~cm}^{-3}\right) \mathrm{Al}_{0.48} \mathrm{In}_{0.52} \mathrm{As}$ contact layer. The sample was grown on $n^{+}$InP and growth was terminated with a protective GaAs cap layer. The entire structure was grown at $460{ }^{\circ} \mathrm{C}$ and the AlInAs layers were grown at $1 \mu \mathrm{m} / \mathrm{h}$. Planar $\mathrm{Au}$ Schottky diodes were formed by evaporation after a $5 \mathrm{~s}$ etch in $\mathrm{HCl}: \mathrm{H}_{2} \mathrm{O}$ (1:1). In the first wafer, the didoes were 120 $\mu \mathrm{m}$ in diameter and spaced $\sim 500 \mu \mathrm{m}$ apart. Measurements were made over an area of $0.7 \mathrm{~cm} \times 0.3 \mathrm{~cm}$. In the sample from the second set, the diodes are $680 \mu \mathrm{m}$ in diameter and spaced $0.1 \mathrm{~cm}$ apart. Measurements on this wafer were made over an area of $1.1 \mathrm{~cm} \times 0.8 \mathrm{~cm}$. It was observed that in the first wafer, $\phi_{\mathrm{Bn}}$ and $n$ were almost uniform at values $0.66-$ 0.68 and 1.1-1.3 over the entire sample size. Only in two regions were $\phi_{\mathrm{Bn}}$ smaller (0.56 and 0.63) and $n$ larger (1.5 and 2.2). In the second wafer, a random variation in the values of $\phi_{\mathrm{Bn}}$ and $n$ were observed over the same sample size. Again, the variation of $\phi_{\mathrm{Bn}}$ was from 0.56 to 0.68 and that of $n$ was from 1.1 to 2.1 . The variation of the diode parameters in the two samples is highlighted in Fig. 1. It may be noted that while mapping with a finer mesh size to determine segregation effects is possible by techniques such as secondary ion mass spectrometry (SIMS), the mesh size in our experiment corresponds to typical device and circuit separations in microwave monolithic and optoelectronic integrated circuits. It is also important to note the role of the GaAs cap layer in these samples. It was incorporated (a) to minimize changes in surface chemistry of Al-bearing compounds after epitaxy, and (b) to avoid degradation during

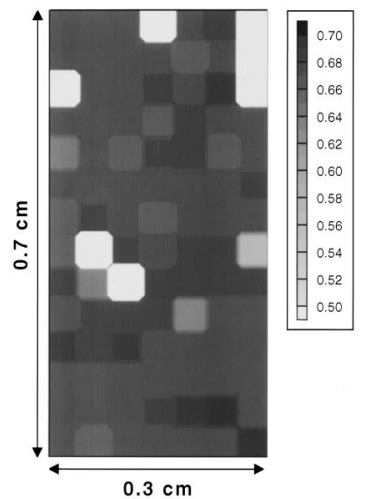

(a)

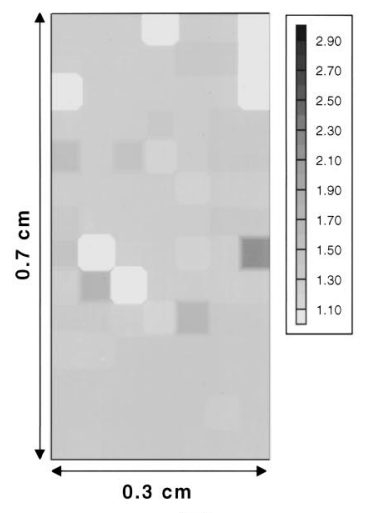

(b)

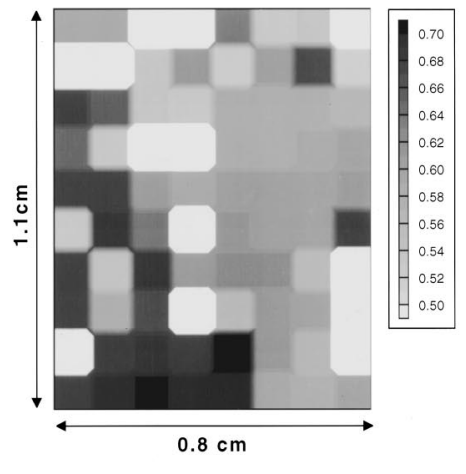

(c)

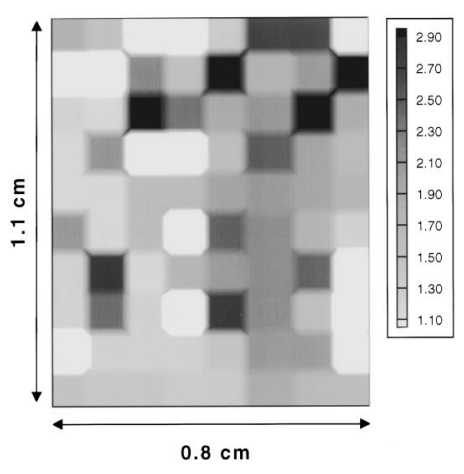

(d)
FIG. 1. Spatial variation of Schottky barrier height $\phi_{\mathrm{Bn}}$ and ideality factor $n$ with growth temperature: (a) and (b) represent variation for a sample grown at $520^{\circ} \mathrm{C}$ and (c) and (d) represent variations for a sample grown at $460{ }^{\circ} \mathrm{C}$. The blank (white) regions represent areas where measurements were not made. The square grid in each figure is representative of a diode at its center.

etching with $\mathrm{HCl}: \mathrm{H}_{2} \mathrm{O}$. During this etching, the surface is cleaned and the native oxide is removed, leaving a $15-40 \AA$ $\mathrm{GaAs}$ layer. Tunneling through such a thin layer will not skew any measurement data; instead, the presence of the GaAs layer enhances the reliability of the data.

It is clear that although the two sets of experiments with Schottky diodes are with apparently different materials, the results indicate striking similarities. Most importantly, it is observed that the two extreme spatially varying values of $n$ corresponds almost exactly to the variation of these parameters obtained by varying the growth temperature. The observed behavior of the measured $\phi_{\mathrm{Bn}}$ is also similar. For growth at $400{ }^{\circ} \mathrm{C}$, the value of $\phi_{\mathrm{Bn}}$ is $0.52 \mathrm{eV}$, which is close to the lowest value of $0.56 \mathrm{eV}$ measured for the range of spatial variation. The value of $\phi_{\mathrm{Bn}}=0.55 \mathrm{eV}$ for material grown at 300 and $500{ }^{\circ} \mathrm{C}$ does not quite match the high value of 0.66 to $0.68 \mathrm{eV}$ in the range of spatial variations, but this is expected due to the averaging of data done in the first experiment. Also, the growth temperatures are a little different and the ambients of the two systems could also be different in the two sets of experiments.

The disparity in bond strengths of the Al-As and either the $\mathrm{In}-\mathrm{As}$ or $\mathrm{Ga}-\mathrm{As}$ is the probable cause of the observed behavior. At low enough temperature, both of the cations will have very little surface mobility and the surface morphology will approximate the random arrival of the atoms on the 
growing surface. As the temperature is increased, the In atoms will become mobile much more quickly than the Al atoms due to the weaker In-As bonds compared to the $\mathrm{Al}-\mathrm{As}$ bonds. There is a similar difference in the surface mobility of $\mathrm{Al}$ and $\mathrm{Ga}$ atoms in the $630-670{ }^{\circ} \mathrm{C}$ substrate temperature range. ${ }^{13,14}$ This diffusion length difference resulting in poor surface morphology causes surface segregation of the more volatile group III element. ${ }^{15}$ The XPS measurement and the data on the Schottky barrier heights confirm such behavior. At $400{ }^{\circ} \mathrm{C}$, the surface segregation of In causes the observed decrease in the Schottky barrier height. This is the kinetic argument for the observed behavior. The data could also be interpreted from a thermodynamic equilibrium model with kinetic limitations at low substrate temperature. If one assumes that the MBE growth conditions are such that a surface layer exists that is close to equilibrium, the degradation in the AlInAs quality could also be related to an alloy miscibility gap that could cause spinodal decomposition. Clustering into Al- and In-rich regions is predicted for growth conditions that approach equilibrium. ${ }^{9}$ The clustering could be maximized at an intermediate growth temperature if one considers the tradeoff in the internal energy (driving the system towards clustering) and entropy (driving the system towards disorder) terms in the free energy. At low temperatures, the $\mathrm{Al}$ and In atoms will probably not have a diffusion length large enough to reach energetically favorable growth conditions. As the temperature is raised, the growth is relieved of the kinetic limitations and clustering results. At higher energies, the entropy term would govern the free energy and clustering will again be reduced.

The observed spatial variation of Schottky diode parameters is consistent with that of a disordered alloy. In the sample grown at $460{ }^{\circ} \mathrm{C}$, the random and large variation in the values of $\phi_{\mathrm{Bn}}$ and $n$ suggest increased clustering and/or surface segregation. On the other hand, spatial variations are almost nonexistent in the sample grown at $520{ }^{\circ} \mathrm{C}$. The barrier height of $0.55 \mathrm{eV}$ corresponds to an In-rich alloy, whereas a value 0.68 probably corresponds to the latticematched composition and reflects a more realistic value of the barrier height for this ternary alloy. ${ }^{16}$ It is also of interest to note that a low value of $\phi_{\mathrm{Bn}} \cong 0.55$ always corresponds to $n \cong 2$. This high value of $n$ can be attributed to two-step trap-assisted tunneling conduction mechanism in the diodes. ${ }^{17}$ One can only surmise that surface segregation and/or clustering are responsible for the creation of these traps. Deep levels, which may have their origins in the clustering phenomena, have been observed. ${ }^{7}$

The authors thank Dr. Y. C. Chen for growth of the Schottky diode samples at the University of Michigan and Professor U. K. Mishra for his help and useful discussions. The work at the University of Michigan was supported by the Army Research Office under Grant No. DAAL03-92-G0109. S. S. acknowledges the support of the Homi Bhaba Fellowship, (India) and P. Zaman acknowledges the support of the Council of Scientific and Industrial Research (India).

${ }^{1}$ J. Pamulapati, R. Lai, G. I. Ng, Y. C. Chen, P. R. Berger, P. K. Bhattacharya, J. Singh, and D. Pavlidis, J. Appl. Phys. 68, 347 (1990).

${ }^{2}$ H. Ohno, J. Barnard, C. E. C. Wood, and L. F. Eastman, IEEE Electron Device Lett. EDL-1, 154 (1980).

${ }^{3}$ U. K. Mishra, A. S. Brown, M. J. Delaney, P. T. Greiling, and C. F. Krumm, IEEE Trans. Microwave Theory Tech. 37, 1279 (1989).

${ }^{4}$ T. D. Hunt, J. Urquhart, J. Thompson, R. W. Davies, and R. H. Wallis, Proceedings of the European Solid State Device Research Conference, Nottingham, U.K., September 1990, p. 117.

${ }^{5}$ W. Gao, A. Khan, P. R. Berger, R. G. Hunsperger, G. Zydzik, H. M. O'Bryan, D. Sivco, and A. Y. Cho, Appl. Phys. Lett. 65, 1930 (1994)

${ }^{6}$ J-W. Seo, C. Caneau, and I. Adesida, IEEE Photon. Technol. Lett. 5, 1313 (1993).

${ }^{7}$ W. P. Hong, A. Chin, N. Debbar, J. Hinckley, P. K. Bhattacharya, and J. Singh, J. Vac. Sci. Technol. B 5, 800 (1987).

${ }^{8}$ A. S. Brown, U. K. Mishra, J. A. Henige, and M. J. Delaney, J. Vac. Sci. Technol. B 6, 678 (1988).

${ }^{9}$ J. Singh, S. Dudley, B. Davies, and K. K. Bajaj, J. Appl. Phys. 60, 3167 (1986).

${ }^{10}$ D. F. Welch, G. W. Wicks, and L. F. Eastman, Appl. Phys. Lett. 43, 762 (1983).

${ }^{11}$ A. S. Brown, M. J. Delaney, and J. Singh, J. Vac. Sci. Technol. B 7, 384 (1989).

${ }^{12}$ Semiconductors, edited by O. Madelung (Springer, Berlin, 1991).

${ }^{13}$ W. I. Wang, S. Judaprawira, C. E. C. Wood, and L. F. Eastman, Appl. Phys. Lett. 38, 708 (1981).

${ }^{14}$ H. Morkoc, T. J. Drummond, W. Kopp, and R. Fischer, J. Electrochem. Soc. 129, 824 (1982).

${ }^{15}$ J. Massies, F. Turco, A. Saletes, and J. P. Contour, J. Cryst. Growth 80, 307 (1987).

${ }^{16}$ W. Gao, P. R. Berger, R. G. Hunsperger, G. Zydzik, W. W. Rhodes, H. M. O'Bryan, D. Sivco, and A. Y. Cho, Appl. Phys. Lett. 66, 3471 (1995).

${ }^{17}$ G. H. Parker and C. A. Mead, Appl. Phys. Lett. 14, 21 (1969). 